\title{
Distinguishing states of awareness from confidence during retrieval: Evidence from amnesia
}

\author{
SUPARNA RAJARAM \\ State University of New York, Stony Brook, New York \\ MARYELLEN HAMILTON \\ St. Peter's College, Jersey City, New Jersey \\ and \\ ANTHONY BOLTON \\ State University of New York, Stony Brook, New York
}

\begin{abstract}
Two experiments were conducted to determine whether recollective experience is distinguishable from confidence. In Experiment 1, we tested college participants in a within-subjects design and replicated Gardiner and Java's (1990) findings from a between-subjects design. We observed higher remember judgments for words than for nonwords, but higher know judgments for nonwords than for words. For confidence judgments, we obtained greater sure than unsure responses for both words and nonwords. In Experiment 2, we tested amnesic participants and matched control participants. Control participants produced the same pattern of results as college participants, but the results of amnesic participants diverged in an important way. For confidence judgments, the amnesic participants, like the control and college participants, made more sure than unsure judgments to both words and nonwords. But for recollective judgments, amnesic participants did not produce the crossover interaction for words and nonwords. This striking difference between the performance of memory-intact and amnesic participants demonstrates that recollective judgments and confidence that accompany retrieval are not isomorphic psychological experiences.
\end{abstract}

One mental activity that permeates much of human existence is memory. Gardiner (2000) recently argued that the most powerful contributions to the study of human memory are likely to come from reports that provide three kinds of converging evidence: a measure of memory performance, a measure of the subjective states of awareness that accompany performance, and evidence about the neural bases that relate to performance and awareness. In this article, we bring together these lines of evidence to answer a question that is at the heart of characterizing states of consciousness in memory. The question we address is whether different states of conscious awareness during retrieval of past information are distinguishable from the level of confidence that people have in these memories. To do so, we report evidence obtained from memory-intact as well as memory-impaired, or amnesic, participants.

The study of states of awareness during memory performance was revolutionized by Tulving (1985) when he

This research was supported by Grant R29MH57345 to S.R. We are grateful to the amnesic participants and their family members for their effort and time. We thank Mana Heydarpour and Richard Delaney for their research assistance. Correspondence concerning this article should be addressed to S. Rajaram, Department of Psychology, State University of New York at Stony Brook, Stony Brook, NY 11794-2500 (e-mail: suparna.rajaram@sunysb.edu). introduced the remember-know paradigm to measure autonoetic and noetic consciousness. Autonoetic consciousness refers to the ability to mentally travel to a point in time in the past and reexperience that moment. Vivid, specific, or contextual details from that moment give rise to this type of awareness. Remember judgments are used to obtain a measure of this type of consciousness. Noetic consciousness refers to the ability to become aware of the occurrence of certain moments or events in the past even though that event can no longer be relived or reexperienced. This awareness can involve personal or public events and is experienced with certainty. But this awareness exists in the form of knowledge of the events and does not include a sense of immediacy, or vivid, specific, or contextual details associated with these events. Know judgments are used to obtain a measure of this type of consciousness.

The remember-know paradigm has proven to be a remarkably successful tool with which to quantify memorial experiences that are essentially subjective (see Gardiner \& Conway, 1999; Gardiner \& Richardson-Klavehn, 2000; Rajaram, 1999; Rajaram \& Roediger, 1997, for reviews of empirical studies). A typical experiment conducted with this paradigm involves three phases: study, distractor, and test. At study, participants are presented with a list of words, pictures, or sentences, and might be asked to per- 
form different kinds of encoding operations on these items. After a distractor period that could last anywhere from 10 min to several days, the test phase is conducted. A majority of published studies have used the recognition memory task to measure memory performance and states of awareness at test. Participants are presented with a list of studied and nonstudied items and are typically asked to first make a recognition judgment and then to assign remember or know judgments to items classified as studied. Extensive and careful instructions (see Gardiner, 1988, and Rajaram, 1996, for detailed instructions) are given to participants to ensure that the remember-know distinction is used appropriately, and guessing is discouraged (see Gardiner \& Conway, 1999).

This procedure yields reliable and replicable patterns of data as a function of theoretically motivated variables so that extant studies show remember and know judgments to be functionally independent and, as such, to be under experimental control. So, principled administrations of independent variables have yielded dissociations where independent variables influence remembering but not knowing (e.g., Gardiner, 1988; Rajaram, 1996, 1998), influence knowing but not remembering (e.g., Gardiner \& Gregg, 1997; Gregg \& Gardiner, 1994; Mäntylä \& Raudsepp, 1996; Rajaram, 1993), influence remembering and knowing in opposite ways (e.g., Gardiner \& Java, 1990; Rajaram, 1993), or influence remembering and knowing in parallel ways (Gardiner, Kaminska, Dixon, \& Java, 1996; Hamilton \& Rajaram, in press; Rajaram \& Hamilton, 2001). Thus, this large body of principled data, collected across different laboratories, supports the validity of this procedure as a means to measure subjective states of awareness.

The theoretical interpretations developed to account for the remember-know findings fall into two broad categories: dual-component accounts and single-component accounts. Several dual-component accounts have been developed in order to understand the remember-know distinction because these two types of judgments, by definition, capture distinct psychological experiences (Gardiner, 1988; Jacoby, Yonelinas, \& Jennings, 1997; Rajaram, 1996; Rajaram \& Roediger, 1997; Rotello, Macmillan, \& Reeder, 2001; Tulving, 1985). Although these dualcomponent accounts differ in their details, all of them converge on an important point: Remember and know states are mediated by two different mechanisms.

For example, Tulving (1985) assumed that the remember judgments measure autonoetic consciousness, which is a feature of the episodic memory system, whereas know judgments measure noetic consciousness, which is a feature of the semantic memory system. Gardiner (1988) also proposed a systems account in which remembering is assumed to tap into the episodic memory system that relies on conceptual processing, and knowing is assumed to tap into the procedural memory system that relies on perceptual processing. In contrast to the systems accounts, Rajaram (1993) proposed a processing account of the remember-know distinction in which remembering was assumed to be influenced by conceptual processes, whereas knowing was assumed to be influenced by perceptual processes. The early data from the literature (Gardiner, 1988; Gardiner \& Java, 1990; Gardiner \& Parkin, 1990; Rajaram, 1993) provided a good fit for both Gardiner's (1988; see also Gardiner \& Parkin, 1990) systems account and Rajaram's (1993) processing account.

Subsequently, these proposals were revised in light of the findings that certain perceptual variables selectively influence remember judgments (Mäntylä, 1997; Rajaram, 1996). Rajaram (1996) proposed a dual-process, distinctivenessfluency framework to account for these and the earlier findings. Subsequent studies have tested, and found support for, the predictions generated from the distinctivenessfluency framework. Specifically, studies have shown that independent variables that enable distinctive processing of the stimuli increase remember judgments regardless of whether the distinctiveness arises from a conceptual or a perceptual basis (Mäntylä, 1997; Rajaram, 1998). Conversely, independent variables that increase the fluency with which stimuli are processed increase know judgments regardless of whether the fluency arises from perceptual or conceptual variables (Conway, Gardiner, Perfect, Anderson, \& Cohen, 1997; Rajaram \& Geraci, 2000).

The dual-component processing accounts of the remember-know distinction also include the independent remember-know (IRK) model proposed by Jacoby et al. (1997). This model also assumes that memory performance is mediated by two different processes termed recollection (or conscious memory processes) and familiarity (unconscious memory processes). Furthermore, these two processes are assumed to operate independently, not redundantly (Joordens \& Merikle, 1993) or by mutual exclusivity. The IRK model states that in the rememberknow paradigm, the remember measure is influenced by the recollective process. The IRK model further states that the standard know measure, derived from the direct reports of participants in most of the dual-component models described earlier, underestimates the influence of the familiarity process on memory performance. As such, the IRK model incorporates the correction know/(1 - remember) to compute the contribution of familiarity.

The relative merits and weaknesses of using these different approaches to measuring the know data are discussed in detail elsewhere (e.g., Jacoby et al., 1997; Parkin, Gardiner, \& Rosser, 1995; Rajaram, 1999; Rajaram \& Roediger, 1997; Richardson-Klavehn, Gardiner, \& Java, 1996) and will not be reviewed here. For the present purposes, it should be noted that the assumptions regarding independence, redundancy, or mutual exclusivity of processes are not relevant to the goals of this study. The present goal is to determine whether remember and know responses are predominantly influenced by two different processes or by a single process, and in that regard, all the dual-component accounts converge.

In our experiments, we used the standard measure of know responses (obtained directly from participants' selfreports). Our main goal was to assess the selective process that influences the remember or the know state of aware- 
ness and to determine whether these processes would influence confidence judgments similarly. This goal is different from computing the contributions of the two processes to overall memory performance. Thus, for present purposes, where two sets of metamemorial judgments (experiential states and confidence) are being compared, the direct measure of know is the appropriate measure to adopt. Furthermore, in the Gardiner and Java study (1990) that forms the backdrop of our experiments, the critical patterns of results remain the same, whether the standard know measure or the IRK know measure is used.

In contrast to the dual-component models of remembering and knowing, the single-component models, based on the signal detection model, postulate a single process to account for the remember-know findings (Donaldson, 1996; Hirshman \& Master, 1997; Inoue \& Bellezza, 1998). According to this view, participants place two thresholds on a single-process continuum so that the more stringent threshold represents the cutoff for remember responses, and the more lenient threshold represents the cutoff for remember plus know, or overall recognition, responses. By shifting these criteria on the continuum, the proponents of the single-process model can account for various dissociations and associations observed for remember-know responses.

In this way, single-process models have predictive power but cannot explain how placement of criteria in certain places on the continuum produces different states of awareness, or why different independent variables produce specific dissociations or associations between these two states of awareness. Furthermore, the predictive power of the single-component trace strength model has also been challenged recently. A central prediction of the singleprocess model is that the bias-free estimates of memory for overall recognition (that includes remember and know judgments) should be equivalent to that obtained for remember judgments alone. But both meta-analyses of a large set of studies (Gardiner \& Conway, 1999; Gardiner, Ramponi, \& Richardson-Klavehn, 2002) and analyses of sets of individual data (Gardiner \& Gregg, 1997) have shown greater bias-free estimates of memory for overall recognition judgments than for remember judgments alone.

Another challenge to the view that states of awareness are reducible to a single, underlying process comes from evidence showing that distinctions in the experiences of remembering and knowing can be linked to different physical or neural bases. So, different patterns of neurophysiological activities have been reported for remember and know responses with the evoked-response potential (ERP) measure (Düzel, Yonelinas, Mangun, Heinze, \& Tulving, 1997; Smith, 1993), and distinct patterns of activation have been observed for remember and know responses in event-related functional magnetic resonance imaging (fMRI; Henson, Rugg, Shallice, Josephs, \& Dolan, 1999). Dissociable remember and know responses have also been observed as a function of left versus right unilateral temporal lobectomy (Blaxton \& Theodore, 1997; Moscovitch \& McAndrews, 2002), as a function of frontal lobe dysfunction (Dalla Barba, 1993), as a function of Alzheimer's disease (Dalla Barba, 1997), and as a function of age (Java, 1996; Mäntylä, 1993; Parkin \& Walter, 1992; Perfect, Williams, \& Anderton-Brown, 1995). Remember and know judgments are also differentially influenced as a function of other diseases such as schizophrenia (Huron et al., 1995) or by psychopharmacological manipulations (Curran, Gardiner, Java, \& Allen, 1993). These findings are problematic for a single-continuum model that cannot explain why remember-know judgments would be influenced in different ways by different cognitive and neural mechanisms.

In this article, we focused on a comparison between remember-know judgments and confidence judgments to determine whether distinct states of awareness are functionally equivalent to the levels of confidence people have in their memories. This comparison between qualitatively different states of awareness on one hand and levels of confidence that vary along a unitary strength continuum on the other, is central to understanding whether states of awareness provide a unique window toward understanding the relationship between conscious experience and memory. To test this question, we selected a variable that quintessentially links awareness and memory: We tested amnesic participants and evaluated their patterns of performance against the performance of matched control participants. Specifically, we examined whether conscious awareness measured by remember-know responses is isomorphic with confidence, or whether remember- know responses capture awareness during retrieval in ways that cannot be measured simply by using confidence judgments.

The hallmark of the amnesic syndrome is the inability to consciously experience again an event that occurred in one's past even though implicit memory for that event might remain intact. Because of this defining characteristic of amnesia, it is logical to expect impairments in the reports of awareness in amnesic participants relative to matched control participants. Indeed, published reports corroborate this prediction and show that although remember judgments are disproportionately, and dramatically, impaired in amnesia, both remember and know judgments are impaired in amnesic participants relative to control participants (Knowlton \& Squire, 1995; Schacter, Verfaellie, \& Pradere, 1996; Verfaellie, Giovanello, \& Keane, 2001; Yonelinas, Kroll, Dobbins, Lazzara, \& Knight, 1998). However, these studies have not directly compared remember-know judgments and confidence judgments in amnesic participants. We reasoned that if remember-know judgments are equivalent to making confidence judgments, amnesic participants should be impaired at making both types of judgments. However, if remember-know judgments and confidence judgments rely on different processes and mechanisms, impairment in making remember-know judgments should not extend to confidence judgments. We tested these hypotheses in this study.

Remember-know judgments and confidence judgments have been shown to present in different ways as a function 
of age (Parkin \& Walter, 1992) and in memory-intact populations as a function of independent variables (Gardiner \& Java, 1990; Holmes, Waters, \& Rajaram, 1998; Mäntylä, 1997; Rajaram, 1993; Tulving, 1985). Although some studies have combined remember-know judgments and confidence judgments within one experiment (Holmes et al., 1998; Tulving, 1985), making it potentially difficult to tease apart the effects on these two classes of responses, other studies have separated these two classes of responses across different experiments. For instance, Rajaram (1993) manipulated the presentation of test words so that the word was either preceded by a masked version of itself, or by an unrelated word, and participants either made remember-know or sure-unsure responses to test words designated as recognized. The masked repetition manipulation selectively increased only know responses but had no effect on remember responses. But a parallel pattern of results - that is, a selective increase in only unsure responses-was not found for confidence judgments. These data show that, contrary to a common concern, know responses are not functionally equivalent to low confidence judgments (see also Parkin \& Walter, 1992).

Similarly, Gardiner and Java (1990) presented two groups of participants with words and nonwords at study; the studied items were intermixed with nonstudied words and nonwords at test. Performance of the group that made remember-know judgments dissociated as a function of the word-nonword variable: The participants gave more remember judgments to words than to nonwords and more know judgments to nonwords than to words. Performance of the group that made sure-unsure judgments only showed a main effect of item type: More sure than unsure responses were given to both words and nonwords.

Single-process signal detection models can account for these different patterns of remember-know and sureunsure responses by shifting the criteria on a continuum (Donaldson, 1996). However, such criterion-placement exercises cannot explain why participants would choose one set of placements in one test situation (rememberknow) and a different set of placements (sure-unsure) in another test situation. In contrast, a theoretical interpretation by which qualitatively distinct experiences at retrieval cannot be reduced to differences in confidence levels provides a nice psychological explanation. A strong test of such an interpretation can be conducted by testing the effects of neurological disorders that produce a deficit in conscious recollective experience on remember-know judgments but not on confidence judgments. In the present study, we compared awareness judgments with confidence judgments in amnesic participants to address this issue from a neuropsychological perspective.

As described earlier, remember-know judgments, and particularly remember judgments, are impaired in amnesia. Thus, if amnesic participants in the present study do not produce the same pattern of dissociation for rememberknow judgments as a function of the word-nonword manipulation as the memory-intact (control) participants, the qualitative, and psychological, distinction between re- member and know judgments would be further validated. The more critical test concerns the outcome with confidence judgments in the context of these remember-know judgments. If remember-know and confidence judgments are psychologically and functionally equivalent, we should observe the pattern of amnesic participants' data to deviate from that of memory-intact (control) participants for both remember-know and confidence judgments. However, if remember-know and confidence judgments have different cognitive and neural bases, we should expect the divergence in the patterns of performance between amnesic participants and control participants for only remember-know judgments, but not for confidence judgments.

\section{EXPERIMENT 1}

We modeled our study after the word-nonword study published by Gardiner and Java (1990). Gardiner and Java reported a different pattern of results for remember-know judgments and confidence judgments by using a betweensubjects design for the two sets of judgments. Because the amnesic participant pool is typically small in the studies reported in the memory literature, as was the case in our Experiment 2, we needed to use a within-subjects design for the two sets of judgments. But before doing that, we conducted a systematic replication of Gardiner and Java's study with a comparable sample of college students to ensure that a within-subjects design would also produce the same pattern of results as that reported by Gardiner and Java. With the exception of this change in design, we followed Gardiner and Java's methodology as closely as possible. Thus, in our study, the same group of college participants made remember-know judgments on one set of stimuli and confidence judgments on another set of stimuli. The remember-know session always came first in all the experiments. Remember-know instructions are more elaborate than confidence judgments, and care was taken to ensure that the participants fully grasped the nature of, and the distinction between, these experiential states. Therefore, this testing order was selected to ensure that confidence judgments did not contaminate the remember-know judgments with a carryover effect to the second session.

\section{Method}

Participants. Twenty undergraduates from SUNY Stony Brook participated for credit as partial requirement for course work. The undergraduates were recruited from the Psychology Department subject pool, and informed consent to participate in the study was obtained.

Materials. Words and nonwords were selected from Gardiner and Java's (1990) experiments. Because we conducted the rememberknow test session and the confidence test session on the same set of participants, we needed twice as many items so that a different set of items could be used in each of these two sessions. Therefore, we used Gardiner and Java's original 60 items and created an additional set of 60 items that were closely matched to the original materials. Specifically, we used a total of 120 , four-letter, one-syllable, pronounceable words and nonwords. For the 60 words, 30 were taken from Gardiner and Java, and 30 were selected to match the original 
materials for word frequency (the Gardiner \& Java set - an average of 122 per million words, our set—an average 118.4 per million, the average frequency for the entire set- 120 per million, Kučera \& Francis, 1967). For the 60 nonwords, 30 were taken from Gardiner and Java. An additional set of 30 nonwords was created so as to include the same vowel-consonant patterns, and the exact letters were used the same number of times as in the original set of nonwords (examples of nonwords: igst, geel, nist).

The set of 120 items were divided into two test lists (List 1 and List 2). Each 60-item list contained 30 words and 30 nonwords (15 from Gardiner \& Java's, 1990, materials, 15 from our new materials for each item type). These two test lists were counterbalanced across the remember-know test session and the confidence test session across subjects. In addition, each test list was further divided in half to counterbalance study and nonstudied items, yielding four study lists.

Following Gardiner and Java's (1990) methodology, all words and nonwords were displayed on $5 \times 3$ in. white index cards. Words were centered and printed in blocked letters in black ink. Two tests were created to present 60 test items ( 30 words and 30 nonwords with half in each set being studied). The test consisted of a sheet of paper with three columns of 20 hand-printed items.

Procedure. Each participant was tested individually. One week elapsed between the remember-know and the confidence sessions. Within each session, the participants were presented with a list of 30 items ( 15 words and 15 nonwords) in a random order. Items were presented for $3 \mathrm{sec}$ each to study for a later, unspecified memory test. The study phase was followed by a 15 -min retention interval. Ten minutes were filled with conversation, and 5 min were used for instructions.

In the following test phase, the participants viewed one item at a time to perform a recognition memory task. The participants circled any item that they believed was from the study episode. If an item was designated as studied, the participants were asked to make an additional judgment before proceeding to the next item on the list. For this judgment, in the Week 1 session, the participants were asked to indicate their subjective experience that accompanied their recognition by providing remember-know judgments to the recognized items and were asked to refrain from guessing. Detailed instructions for making remember-know judgments were adapted from Rajaram (1993). To further ensure that the participants understood the instructions, they were again asked to explain the difference between remember and know judgments with concrete examples from the list at the end of the test phase. All participants in this and the next experiment were strongly discouraged from guessing (see Gardiner \& Gregg, 1997; Gardiner, Richardson-Klavehn, \& Ramponi, 1997). The comparable false alarm rates we obtained in our experiments with those reported by others indicate that the participants successfully followed our instructions.

In the Week 2 session, the judgment following positive recognition consisted of making confidence judgments. Specifically, the participants were instructed to decide whether they were absolutely sure that they recognized the item (sure judgment) or whether they were fairly confident but not absolutely sure that they recognized an item (unsure judgment). Once again, guessing was discouraged. Both tests were self-paced and were completed in less than 5 min.

\section{Results and Discussion}

The alpha level in all the experiments was set at $p<$ .05 , unless noted otherwise. The left panel of Figure 1 displays the mean proportion of remember-know responses, and the right panel displays the mean proportion of sure-unsure responses to words and nonwords. The false alarm rates were low and comparable with the rates reported in the literature (remember-word $=.01$, remembernonword $=.02, \mathrm{know}$-word $=.03$, know-nonword $=.12$, sure-word $=.02$, sure-nonword $=.01$, unsure-word $=$ .06 , unsure-nonword $=.05$ ).

The patterns of remember and know responses to words and nonwords were submitted to a two-way analysis of variance (ANOVA) that revealed no significant effect of item type $(F<1)$, no significant effect of response type $(F<1)$, and a significant interaction between these factors $\left[F(1,19)=6.99, M S_{\mathrm{e}}=0.05\right]$. The nature of this crossover interaction was such that the participants gave more remember responses to words than to nonwords, whereas they gave more know responses to nonwords than to words.

The patterns of sure and unsure responses to words and nonwords were submitted to a two-way ANOVA that revealed no significant effect of item type $[F(1,19)=1.86$, $\left.M S_{\mathrm{e}}=0.02\right]$, a significant effect of response type $\left[F(1,19)=33.65, M S_{\mathrm{e}}=0.04\right]$, and a significant interaction between these two factors $\left[F(1,19)=11.88, M S_{\mathrm{e}}=\right.$ $0.02]$. The main effect of response type was a function of a higher proportion of sure responses than of unsure responses for both words and nonwords. The interaction resulted from a larger difference between sure and unsure
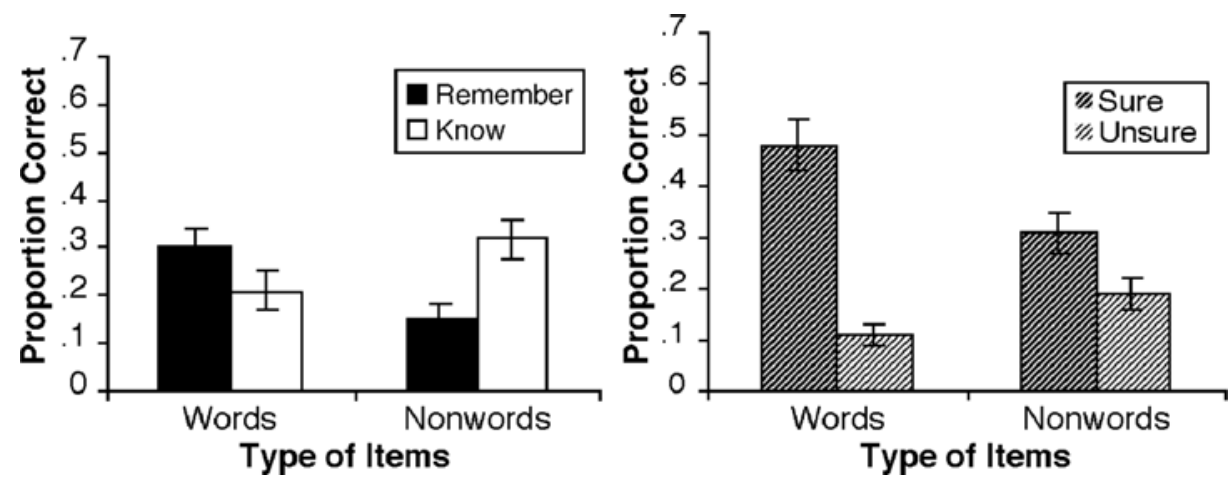

Figure 1. The left panel displays recognition, remember, and know responses, and the right panel displays recognition, sure, and unsure responses of college participants as a function of words and nonwords in Experiment 1. 
responses for words than for nonwords. But because parallel effects were obtained for words and nonwords, the interpretation of the main effect is not qualified by the interaction.

The crossover interaction observed for rememberknow responses and the main effect obtained for sureunsure responses in our within-subjects design replicate the patterns reported by Gardiner and Java (1990) for these two sets of responses. With this replication in place, we conducted the next experiment with amnesic and matched-control participants.

\section{EXPERIMENT 2}

Amnesic and control participants were tested to determine whether the experiential judgments and confidence judgments of amnesic participants would differ from those of matched controls. We predicted that matched controls would demonstrate the dissociative pattern of remember-know judgments for words and nonwords and higher proportions of sure than unsure judgments for both words and nonwords, as shown by the college participants in Experiment 1 in a within-subjects design and by the college participants in Gardiner and Java's (1990) study in a between-subjects design. For amnesic participants, we predicted that their confidence judgments would not differ from those of the controls or college participants. For remember-know judgments, we predicted that amnesic participants would show a different pattern from that observed with controls and college students because amnesia is characterized by a deficit in the subjective experience of retrieval.

\section{Method}

The details of methodology in this experiment were identical to those of Experiment 1, except where noted otherwise.

Participants. Nine amnesic participants and 9 control participants matched for age and education took part (see
Table 1 for participant characteristics). All participants provided informed consent and were paid for their participation.

Procedure. The control participants were treated identically to the college participants in Experiment 1 . The procedure for testing amnesic participants differed from that for the control participants in the following ways: (1) Items were exposed for $10 \mathrm{sec}$ each at study; (2) the retention interval was reduced to $5 \mathrm{~min}$ (the time needed to provide detailed test instructions); and (3) a card displaying the remember-know instructions (or sure-unsure instructions) was in full view throughout the testing period for amnesic participants. These changes in procedure were made to avoid floor effects in performance, and these parameters were calibrated on the basis of a pilot study (with different materials) that we had conducted with amnesic participants.

\section{Results and Discussion}

Control participants. The false alarm rates for this group were comparable with the rates reported in the literature, including those in the Gardiner and Java (1990) study (remember-word $=.02$, remember-nonword $=.01$, know-word $=.03$, know-nonword $=.17$, sure-word $=$ .04 , sure-nonword $=.04$, unsure-word $=.09$, unsurenonword $=.10$ ).

A two-way ANOVA conducted on the patterns of remember and know responses to words and nonwords revealed no significant effect of item type $(F<1)$, no significant effect of response type $\left[F(1,8)=3.24, M S_{\mathrm{e}}=0.03\right]$, and a significant interaction between these factors $[F(1,8)=$ $\left.10.11, M S_{\mathrm{e}}=0.08\right]$. Once again, the crossover interaction resulted from the participants' giving more remember responses to words than to nonwords and their giving more know responses to nonwords than to words (see Figure 2, left panel).

A two-way ANOVA conducted on sure and unsure responses to words and nonwords produced no significant effect of item type $\left[F(1,8)=1.03, M S_{\mathrm{e}}=0.02\right]$, a signif-

Table 1

Characteristics of Amnesic Participants in Experiment 2

\begin{tabular}{|c|c|c|c|c|c|c|c|}
\hline \multirow[b]{2}{*}{ Participant } & \multirow[b]{2}{*}{ Age } & \multirow[b]{2}{*}{ Etiology } & \multirow[b]{2}{*}{ Education } & \multirow{2}{*}{$\begin{array}{c}\text { WAIS-R } \\
\text { (Full-Scale IQ) }\end{array}$} & \multicolumn{3}{|c|}{$\begin{array}{c}\text { WMS-R } \\
\text { (Index Scores) }\end{array}$} \\
\hline & & & & & Gen & Attn & Delay \\
\hline J.S. & 46 & anoxia & 15 & 112 & 89 & 118 & 50 \\
\hline E.T. & 55 & encephalitis & 12 & 102 & 87 & 90 & 62 \\
\hline J.G. & 26 & stroke & 16 & 99 & $<50$ & 74 & $<50$ \\
\hline S.D. & 43 & epilepsy & 16 & 116 & 92 & 120 & 83 \\
\hline W.D. & 61 & unknown & 12 & 104 & 96 & 100 & 70 \\
\hline D.B. & 39 & $\mathrm{CHI}$ & 14 & 102 & 98 & 110 & 92 \\
\hline R.G. & 50 & unknown & 16 & 113 & 90 & 115 & 86 \\
\hline L.L. & 62 & stroke & 14 & 121 & 76 & 138 & 68 \\
\hline M.Q. & 23 & CHI & 14 & 106 & 101 & 125 & 86 \\
\hline Mean & 45.00 & & 14.33 & 108.33 & 86.56 & 110.00 & 71.89 \\
\hline \multicolumn{8}{|c|}{ Matched controls $(N=9)$} \\
\hline Mean & 45.78 & & 15.11 & & & & \\
\hline
\end{tabular}



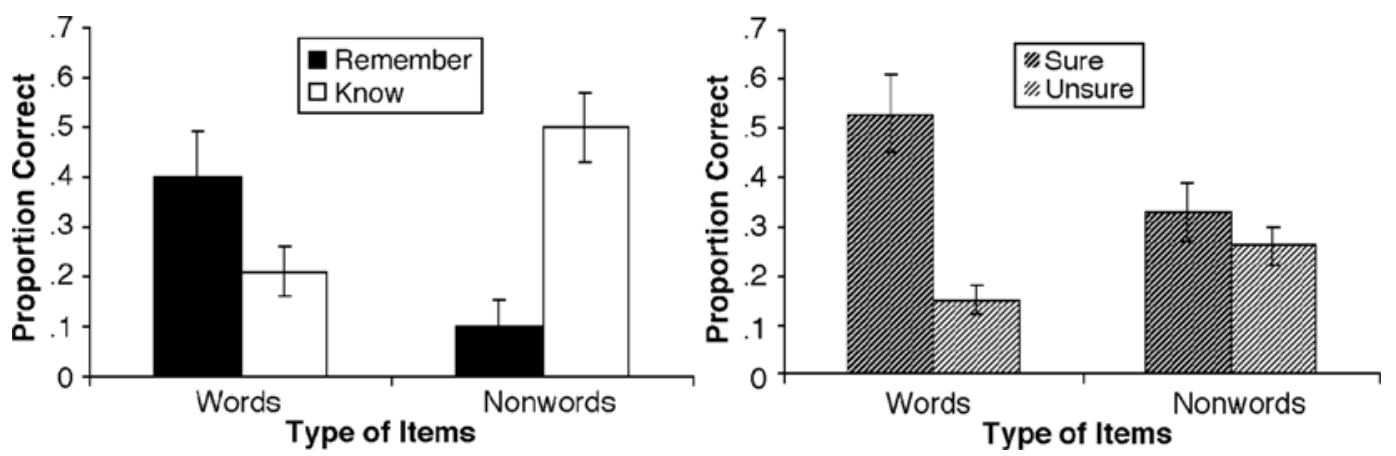

Figure 2. The left panel displays recognition, remember, and know responses, and the right panel displays recognition, sure, and unsure responses of matched control participants as a function of words and nonwords in Experiment 2 .

icant effect of response type $\left[F(1,8)=11.92, M S_{\mathrm{e}}=\right.$ 0.04], and a significant interaction between these two factors $\left[F(1,8)=8.08, M S_{\mathrm{e}}=0.03\right]$. As with the data from the college participants in Experiment 1, the results from the matched controls showed that the main effect of response type was a function of a higher proportion of sure responses than of unsure responses for both words and nonwords. This sure-unsure difference was bigger for words than for nonwords, resulting in an interaction, but the overall pattern shows parallel effects of response type across words and nonwords (see Figure 2, right panel).

The crossover interaction observed for rememberknow responses and the main effect obtained for sureunsure responses with our smaller $N$ of matched controls replicate the results of Experiment 1 with the college participants and the patterns reported by Gardiner and Java (1990).

Amnesic participants. The false alarm rates for this group were also comparable with the rates reported in the Gardiner and Java (1990) study (remember-word $=.07$, remember-nonword $=.10$, know-word $=.13$, knownonword $=.16$, sure-word $=.13$, sure-nonword $=.07$, unsure-word $=.09$, unsure-nonword $=.16$ ).
The pattern of results with the amnesic participants for remember and know responses diverged from those observed with the college participants (Experiment 1) and the control group matched for age, education, and sample size. Specifically, in a two-way ANOVA, there was no significant effect of item type $(F<1)$ or of response type $(F<1)$, and importantly, no significant interaction between the two variables $(F<1$; see Figure 3, left panel). The absence of a crossover interaction underscores the difficulty that amnesic participants experience with making recollective judgments.

In contrast, the pattern of results with sure and unsure responses was found be similar in the amnesic group to the patterns observed with the college participants and matched controls. Specifically, a two-way ANOVA revealed no significant effect of item type $(F<1)$ but a significant effect of response type $\left[F(1,8)=6.03, M S_{\mathrm{e}}=\right.$ $0.05]$. There was no significant interaction between these two factors $\left[F(1,8)=1.56, M S_{\mathrm{e}}=0.04\right]$ (see Figure 2, right panel). As with the data from the college participants in Experiment 1 and the matched controls in Experiment 2, the results from the amnesic participants showed that the main effect of response type was a function of a
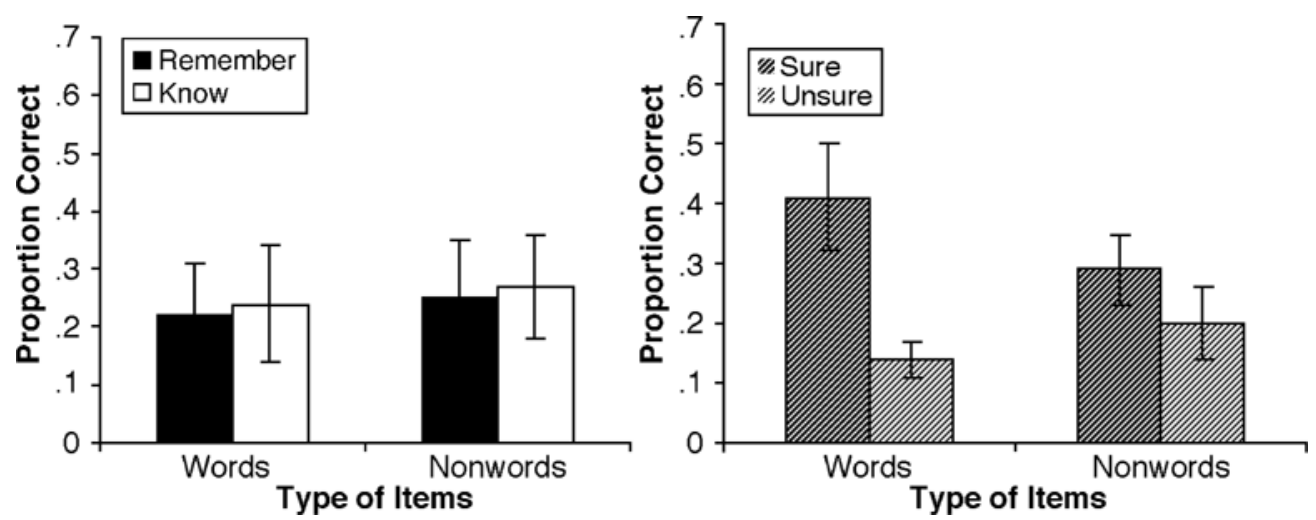

Figure 3. The left panel displays recognition, remember, and know responses, and the right panel displays recognition, sure, and unsure responses of amnesic participants as a function of words and nonwords in Experiment 2. 
higher proportion of sure responses than of unsure responses for both words and nonwords.

The crossover interaction observed for rememberknow responses and the main effect obtained for sureunsure responses with our smaller $N$ of matched controls replicate the results of Experiment 1 with the college participants and the patterns reported by Gardiner and Java (1990). Thus, the memory-intact participants across the two experiments in our study and those in Gardiner and Java's study performed similarly.

The performance of the amnesic participants in our study diverged from that of the matched controls in theoretically important ways. As we predicted, the amnesic participants were impaired in making remember-know judgments and did not exhibit a crossover interaction for words and nonwords, which we observed in the matched control group. This divergent pattern of responses is supported by a significant three-way interaction for subjects (control/amnesic), responses (remember/know), and item (word/nonword) $\left[F(1,16)=3.62, M S_{\mathrm{e}}=0.11\right]$. In contrast, the amnesic group showed the same pattern as the matched control group for sure-unsure responses, thereby producing no interaction among the variables of subjects (control/amnesic), responses (sure/unsure), and item (word/ nonword) $(F<1)$. Together, these findings clearly differentiate the psychological distinction between rememberknow and confidence judgments and provide strong evidence in favor of a dual-component account of states of awareness.

\section{GENERAL DISCUSSION}

In this study, we have brought together evidence from three sources-performance, awareness, and brain function - to assess the nature of conscious awareness in memory. Evidence from memory-intact participants (both college participants and matched controls) confirmed previous findings and showed that states of awareness that accompany memory performance and levels of confidence that accompany memory performance are sensitive to independent variables in very different ways. Although these patterns could be described by single-process, signal detection models by adjusting the placement of criteria on a single continuum, the selection of such placements cannot be readily understood in psychological terms. This difficulty is particularly striking when we consider the data obtained in the present study from the amnesic participants. Even though the pattern of remember-know judgments made by amnesic participants diverged from the patterns of data from the control participants, the confidence data did not show such divergence. These differences and similarities in the performance and awareness of different subject populations strongly support the proposal that states of awareness are not experientially interchangeable with levels of confidence. Thus, although we could find a way to describe each individual set of data from our participants along a single-process continuum, these data, when considered together, are better explained by a dualcomponent account.
The self-reports provided by our amnesic participants during testing are also telling in this respect: The amnesic participants in our study found the task of having to make experiential judgments of remembering and knowing quite difficult but found the task of making confidence judgments much less so. We note this point here to highlight the difference between these two types of judgments and to also share with other researchers this observation so as to aid research being conducted in other laboratories with special populations.

Finally, our study highlights the value of data obtained from participants with neuropsychological disorders in understanding both the disorders of cognition and the functioning of normal cognition.

\section{REFERENCES}

Blaxton, T. A., \& Theodore, W. H. (1997). The role of the temporal lobes in recognizing visuospatial materials: Remembering versus knowing. Brain \& Cognition, 35, 5-25.

Conway, M. A., Gardiner, J. M., Perfect, T. J., Anderson, S. J., \& Cohen, G. (1997). Changes in memory awareness during learning: The acquisition of knowledge by psychology undergraduates. Journal of Experimental Psychology: General, 126, 393-413.

Curran, H. V., Gardiner, J. M., Java, R. I., \& Allen, D. (1993). Effects of lorazepam upon recollective experience in recognition memory. Psychopharmacology, 110, 374-378.

Dalla Barba, G. (1993). Confabulation: Knowledge and recollective experience. Cognitive Neuropsychology, 10, 10-20.

Dalla Barba, G. (1997). Recognition memory and recollective experience in Alzheimer's disease. Memory, 5, 657-672.

DonALDSON, W. (1996). The role of decision processes in remembering and knowing. Memory \& Cognition, 24, 523-533.

Düzel, E., Yonelinas, A. P., Mangun, G. R., Heinze, H. J., \& TulVING, E. (1997). Event-related brain potential correlates of two states of conscious awareness in memory. Proceeding sof the National Academy of Sciences, 94, 5973-5978.

GARDINER, J. M. (1988). Functional aspects of recollective experience. Memory \& Cognition, 16, 309-313.

GARDINER, J. M. (2000). On the objectivity of subjective experiences of autonoetic and noetic consciousness. In E. Tulving (Ed.), Memory, consciousness, and the brain: The Tallinn conference (pp. 159-172). Philadelphia: Psychology Press.

GARDINER,J. M., \& CONWAY, M. A. (1999). Levels of awareness and varieties of experience. In B. H. Challis \& B. M. Velichovsky (Eds.), Stratification of consciousness and cognition (pp. 237-254). Philadelphia: John Benjamin.

GARDiner, J. M., \& GREgG, V. H. (1997). Recognition memory with little or no remembering: Implications for a detection model. Psychonomic Bulletin \& Review, 4, 474-479.

GARDINER, J. M., \& JAVA, R. I. (1990). Recollective experience in word and nonword recognition. Memory \& Cognition, 18, 23-30.

Gardiner, J. M., Kaminska, Z, Dixon, M., \& JaVA, R. I. (1996). Repetition of previously novel melodies sometimes increases both remember and know responses in recognition memory. Psychonomic Bulletin \& Review, 3, 366-371.

Gardiner, J. M., \& PArkin, A. J. (1990). Attention and recollective experience in recognition memory. Memory \& Cognition, 18, 579-583.

Gardiner, J. M., Ramponi, C., \& Richardson-Klavehn, A. (2002). Recognition memory and decision processes: A meta-analysis of remember, know, and guess responses. Memory, 10, 83-98.

Gardiner, J. M., \& Richardson-Klavehn, A. (2000). Remembering and knowing. In E. Tulving \& F. I. M. Craik (Eds.), The Oxford handbook of memory (pp. 229-244). New York: Oxford University Press.

Gardiner, J. M., Richardson-Klavehn, A., \& Ramponi, C. (1997). On reporting recollective experiences and "direct access to memory systems." Psychological Science, 8, 391-394.

GregG, V. H., \& Gardiner, J. M. (1994). Recognition memory and awareness: A large effect of study-test modalities on "know" re- 
sponses following a highly perceptual orienting task. European Journal of Cognitive Psychology, 6, 137-147.

Hamilton, M., \& RAJARAm, S. (2001). States of awareness across multiple memory tasks: Obtaining a "pure" measure of conscious recollection. Acta Psychologica.

Henson, R. N. A., Rugg, M. D., Shallice, T., Josephs, O., \& Dolan, R. J. (1999). Recollection and familiarity in recognition memory: An event-related functional magnetic resonance imaging study. Journal of Neuroscience, 19, 3962-3972.

Hirshman, E., \& Master, S. (1997). Modeling the conscious correlates of recognition memory: Reflections on the remember-know paradigm. Memory \& Cognition, 25, 345-351.

Holmes, J. B., Waters, H. S., \& Rajaram, S. (1998). The phenomenology of false memories: Episodic content and confidence. Journal of Experimental Psychology: Learning, Memory, \& Cognition, 24, 1026-1040.

Huron, C., Danion, J. M., Giacomoni, G., Grange, D., Robert, P., \& Rizzo, L. (1995). Impairment of recognition memory with, but not without, conscious recollection in schizophrenia. American Journal of Psychiatry, 152, 1737-1742.

Inoue, C., \& Bellezza, F. S. (1998). The detection model of recognition using know and remember judgments. Memory \& Cognition, 26, 299-308.

JAcoby, L. L., Yonelinas, A. P., \& Jennings, J. M. (1997). The relation between conscious and unconscious (automatic) influences: A declaration of independence. In J. D. Cohen \& J. W. Schooler (Eds.), Scientific approaches to the question of consciousness (pp. 13-47). Mahwah, NJ: Erlbaum.

JAVA, R. I. (1996). Effects of age on state of awareness following implicit and explicit word association tasks. Psychology \& Aging, 11, 108-111.

Joordens, S., \& Merikle, P. M. (1993). Independence or redundancy? Two models of conscious and unconscious influences. Journal of Experimental Psychology: General, 122, 462-467.

Knowlton, B. J., \& SQuire, L. R. (1995). Remembering and knowing: Two different expressions of declarative memory. Journal of Experimental Psychology: Learning, Memory, \& Cognition, 21, 699-710.

KuČERA,H., \& FranCIS, W. N. (1967). Computationalanalysis of presentday American English. Providence, RI: Brown University Press.

MäNTY LÄ, T. (1993). Knowing but not remembering: Adult age differences in recollective experience. Memory \& Cognition, 21, 379-388.

MäNTY Lё, T. (1997). Recollections of faces: Remembering differences and knowing similarities. Journal of Experimental Psychology: Learning, Memory, \& Cognition, 23, 1203-1216.

MäNTY LÄ, T., \& RAUDSEPP, J. (1996). Recollective experience following suppression of focal attention. European Journal of Cognitive Psychology, 8, 195-203.

Moscovitch, D. A., \& McAndrews, M. (2002). Material-specific deficits in "remembering" in patients with unilateral temporal lobe epilepsy and excisions. Neuropsychologia, 17, 25-35.

Parkin, A. J., Gardiner, J. M., \& Rosser, R. (1995). Functional aspects of recollective experience in face recognition. Consciousness \& Cognition, 4, 387-398.
PARKin, A. J., \& WAlter, B. (1992). Recollective experience, normal aging, and frontal dysfunction. Psychology \& Aging, 7, 290-298.

Perfect, T. J., Williams, R. B., \& Anderton-Brown, C. (1995). Age differences in reported recollective experience are due to encoding effects, not response bias. Memory, 3, 169-186.

RAJARAM, S. (1993). Remembering and knowing: Two means of access to the personal past. Memory \& Cognition, 21, 89-102.

Rajaram, S. (1996). Perceptual effects on remembering: Recollective processes in picture recognition memory. Journal of Experimental Psychology: Learning, Memory, \& Cognition, 22, 365-377.

RAJARAM, S. (1998). The effects of conceptual salience and perceptual distinctiveness on conscious recollection. Psychonomic Bulletin \& Review, 5, 71-78.

RAJARAM, S. (1999). Assessing the nature of retrieval experience: Advances and challenges. In B. H. Challis \& B. M. Velichovsky (Eds.), Stratification of consciousness and cognition (pp. 255-275). Philadelphia: John Benjamin.

Rajaram, S., \& Geraci, L. (2000). Conceptual fluency selectively influences knowing. Journal of Experimental Psychology: Learning, Memory, \& Cognition, 26, 1070-1074.

Rajaram, S., \& Hamilton, M. (2001, July). Effects of contextual variability at encoding on remembering and knowing. Paper presented at the 3rd International Conference on Memory, Valencia, Spain.

Rajaram, S., \& Roediger, H. L., III (1997). Remembering and knowing as states of consciousness during recollection. In J. D. Cohen \& J. W. Schooler (Eds.), Scientific approaches to the question of consciousness (pp. 213-240). Hillsdale, NJ: Erlbaum.

Richardson-Klavehn, A., Gardiner, J. M., \& JaVA, R. I. (1996). Memory: Task dissociations, process dissociations, and dissociations of awareness. In G. Underwood (Ed.), Implicit cognition (pp. 85-158). Oxford: Oxford University Press.

Rotello, C. M., Macmillan, N. A., \& Reeder, J. A. (2001, November). A two-dimensional signal detection model of remember-know judgments. Paper presented at the 42nd Annual Meeting of the Psychonomic Society, Orlando, FL.

Schacter, D. L., Verfaellie, M., \& Pradere, D. (1996). The neuropsychology of memory illusions: False recall and recognition in amnesic patients. Journal of Memory \& Language, 35, 319-344.

SмIтн, M. E. (1993). Neuropsychological manifestations of recollective experience during recognition memory judgments. Journal of Cognitive Neuroscience, 5, 1-13.

Tulving, E. (1985). Memory and consciousness. Canadian Psychologist, 26, 1-12.

Verfaellie, M., Giovanello, K. S., \& Keane, M. M. (2001). Recognition memory in amnesia: Effects of relaxing response criteria. Cognitive, Affective, \& Behavioral Neuroscience, 1, 3-9.

Yonelinas, A. P., Kroll, N. E. A., Dobbins, I., Lazzara, M., \& KNIGHT, R. T. (1998). Recollection and familiarity deficits in amnesia: Convergence of remember-know, process dissociation, and ROC data. Neuropsychology, 12, 323-339.

(Manuscript received January 4, 2002; revision accepted for publication May 13, 2002.) 